\title{
The Development Mode of Teaching Staff in Chinese Undergraduate Universities
}

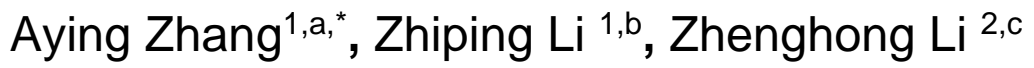 \\ ${ }^{1}$ Harbin University, 150086 Harbin, China \\ ${ }^{2}$ Harbin Institute of Technology, 150001 Harbin, China \\ a,*zaying@sina.com, blizp2008@126.com, c273662999@qq.com
}

Keywords: Development model, Teaching staff, Undergraduate, Universities.

\begin{abstract}
The basic principles of faculty building in undergraduate universities include the basic principles of selecting teachers, using teachers, cultivating teachers and stabilizing teachers. According to the theory of human resource management, the basic mechanisms of faculty building in undergraduate universities include attraction mechanism, competition mechanism, incentive mechanism, flow mechanism, restraint mechanism, growth mechanism, evaluation mechanism and exit mechanism. According to the law of running an undergraduate university, the basic contents of the construction of the faculty in an undergraduate university mainly include the construction plan of the faculty, the selection and allocation of teachers, the training and growth of teachers, the evaluation and reward of teachers, the construction of academic (disciplinary) teams and academic (disciplinary) leaders. The undergraduate universities formulate a plan for the construction of the faculty in accordance with the needs of personnel training, scientific research and school development. The teaching staff construction plan includes construction objectives, plans and specific measures.
\end{abstract}

\section{Basic principles for the construction of teaching staff in undergraduate university}

According to the theory of human resource management, the basic principles of faculty building in undergraduate universities include the basic principles of selecting teachers, using teachers, cultivating teachers and stabilizing teachers.

\subsection{The basic principles of selecting teachers}

\subsubsection{Strict selection principle}

The selection of teachers is the starting point for the construction of teaching staff. The selection of teachers should be carried out strictly according to the post standards so as to select dozens of good teachers and lay a foundation for the good use, education and stability of teachers.

1.1.2 Post matching principle

The selection of teachers should be based on post analysis, post assignment, post assignment, post assignment, post assignment, post assignment, etc. The selected teachers should make the best use of their talents and apply them to match their abilities with their posts.

1.1.3 Objective and impartial principle

The selection of teachers should be carried out on a fair, just and reasonable standard.

\subsection{The basic principles of using teachers}

\subsubsection{Principle of quantity before use}

Teachers should be placed in positions that are necessary and suitable, so as to avoid big or small use. 1.2.2 Principle of reasonable remuneration

Based on distribution according to work, consideration should be given to performance and contribution.

\subsubsection{Double incentive principle}

A system is set up to promote material and spiritual incentives. 


\subsection{The basic principles of nurturing teachers}

\subsubsection{Timely and effective principle}

In accordance with the requirements of knowledge economy, teachers' knowledge can be updated in time and effectively.

\subsubsection{Principle of learning to apply}

Teachers' knowledge growth should aim at meeting the needs of teaching and scientific research, which is, laying a knowledge foundation for teachers' teaching and scientific research.

1.3.3 Principle of teaching students in accordance with their aptitude

Because teachers' personality, foundation, experience, experience, acceptance ability, interest and hobbies are different. Therefore, teachers' training should adopt different methods and forms according to different situations.

\subsection{The basic principles of stabilizing teachers}

\subsubsection{The principle of emotional retention}

We should be moved by feelings, moving with affection and keeping people in love.

\subsubsection{Principle of retention}

Create atmosphere and create opportunities and opportunities for teachers' career development.

\subsubsection{Principle of treatment and retention}

On the basis of teachers' achievements and contributions, and on the principle of distribution according to work, teachers' material treatment and spiritual quality of life are constantly improved.

\section{Basic mechanism of teaching staff construction in Undergraduate Universities}

According to the theory of human resource management, the basic mechanisms of faculty building in undergraduate universities include attraction mechanism, competition mechanism, incentive mechanism, flow mechanism, restraint mechanism, growth mechanism, evaluation mechanism and exit mechanism.

\subsection{Attraction mechanism}

It refers to the flourishing academic career, the relaxed and elegant academic environment, the United and cooperative academic team, the widely influential academic achievements, and the fair and reasonable salary system formed by the undergraduate universities and colleges.

\subsection{Competition mechanism}

It refers to the system formed by undergraduate universities in which teachers of the fittest position and the best position compete for the post on the principle of openness, fairness and preference, on the basis of post-performance, on the link of appointment and promotion, etc.

\subsection{Excitation mechanism}

It refers to the teacher distribution system formed by undergraduate universities on the principle of distribution according to work and on the basis of achievements and contributions.

\subsection{Mobile mechanism}

It refers to the system of teacher flow formed by undergraduate universities to stabilize the contingent of subject leaders and academic leaders, rationally allocate human resources and rationally flow talents.

\subsection{Constraint mechanism}

It refers to the establishment and perfection of academic system, the implementation of post appointment system, the standardization of teachers' academic behavior and the restraint and self-restraint system of teachers' academic work formed by undergraduate universities. 


\subsection{Growth mechanism}

It refers to the teacher training system and the young teacher tutor system formed by undergraduate universities. Teachers master the educational laws and theories, advanced teaching methods and modern educational technology, and can carry out creative scientific research and teaching activities.

\subsection{Evaluation mechanism}

It refers to the perfection and perfection of the evaluation system of teachers' academic level formed by undergraduate universities, and the evaluation system of teachers' academic level of teaching, scientific research and academic level, post-performance and so on.

\subsection{Exit mechanism}

It refers to the mechanism of unqualified teachers withdrawing from the ranks of teachers according to the appointment system and other regulations of undergraduate universities.

\section{Development mode of teaching staff in Undergraduate Universities}

According to the law of running an undergraduate university, the basic contents of the construction of the faculty in an undergraduate university mainly include the construction plan of the faculty, the selection and allocation of teachers, the training and growth of teachers, the evaluation and reward of teachers, the construction of academic (disciplinary) teams and academic (disciplinary) leaders, etc.

\subsection{Planning of teaching staff in Undergraduate Universities}

The undergraduate universities formulate a plan for the construction of the faculty in accordance with the needs of personnel training, scientific research and school development. The teaching staff construction plan includes construction objectives, plans and specific measures. It is noteworthy that both the teaching and research-oriented colleges and universities can aim at building a team of teachers with reasonable structure, good quality and dedication to work. However, the main function of teaching-oriented colleges is to cultivate talents, while the main function of research-oriented colleges is to cultivate talents, scientific research and so on.

Therefore, the professional quality of teachers in teaching-oriented colleges and universities mainly requires the academic level of teaching, while the professional quality of teachers in research-oriented colleges and universities requires both academic level of teaching and scientific research. Therefore, the same connotation of "reasonable structure and good quality" is different.

\subsection{Selection and allocation of undergraduate teachers}

The selection and allocation of undergraduate teachers is the first measure to achieve the goal of teaching staff. The selection and allocation of teachers should follow the principle of job matching and objective justice. Firstly, we should analyze the positions and make up and decide the positions and functions of the teachers, then select the teachers according to fair, just and reasonable standards, and finally select the teachers to make the best use of their talents and apply them, so as to match their abilities with their posts.

\subsection{Training and growth of undergraduate teachers}

The training and growth of undergraduate teachers is the second measure to achieve the goal of teachers' team building. Teachers' training and growth should follow the principles of timely and effective, teaching students in accordance with their aptitude, and apply the principle of learning to apply.

In order to meet the needs of talent training and scientific research, schools should update teachers' knowledge timely and effectively, and adopt different methods and methods to train teachers according to their differences in professional basis, teaching experience and scientific research ability. Moreover, the growth of teachers' knowledge should not only meet the needs of 
current teaching and scientific research, but also meet the needs of future teaching and scientific research.

\subsection{Evaluation and reward of undergraduate teachers}

The evaluation and reward of undergraduate teachers is the third measure to achieve the goal of teaching staff construction. The evaluation and reward of undergraduate teachers should follow the principle of reasonable reward and double incentive.

That is to say, on the basis of establishing and perfecting the evaluation system of teachers' academic level, undergraduate universities should scientifically and rationally evaluate teachers' academic level of teaching, scientific research and academic level, and post-performance. It also establishes a teacher distribution system based on the principle of distribution according to work, performance and contribution, and preferential treatment for those with more work and more merit, as well as a preferential mechanism for appointment, appointment and promotion.

\subsection{Construction of academic team and academic leader in Undergraduate Universities}

The construction of academic teams and academic leaders in undergraduate universities is the core measure to achieve the goal of faculty building. Excellent academic (subject) leaders are the symbol of the strength, status and prestige of a school and the main cultivators of campus culture and characteristics. The advantages of a discipline often coexist with excellent subject leaders, so some scholars say that excellent subject leaders are the foundation of the discipline and even the school. Therefore, the construction of outstanding academic leaders is the most important part of the construction of teaching staff. The construction of excellent academic (discipline) leaders should follow the growth law of academic (discipline) leaders, create a policy environment, a humanistic environment and an academic environment in which academic (discipline) leaders play their role, and be tolerant and tolerant of academic (discipline) leaders.

According to the concept of using modern talents without asking for ownership but only for use, one of the common measures for the construction of academic (discipline) leaders in undergraduate universities is to introduce flexible talents, that is, not relocating residence registration, not changing establishment, intellectual flow (teacher sharing, project cooperation, etc.), contract management. The introduction of flexible talents has laid the foundation for the sharing of outstanding academic leaders. In the course of building academic leaders, we should also do well in academic (discipline) team building. On the one hand, academic (discipline) leaders should have good personality charm, organizational ability and coordination ability, on the other hand, academic (discipline) teams should form echelon, forming a common vision, Discipline Paradigm and team spirit. In this way, the result of the construction of academic (discipline) teams and academic (discipline) leaders is to form a team of teachers with reasonable structure, good quality and dedication.

\section{Acknowledgement}

This research was financially supported by Heilongjiang Social Science Foundation (Grant No. 17SHD204).

\section{References}

[1] Z. P. Li, H. B. Zhang and et al: Heilongjiang Researches on Higher Education vol. 10 (2006), pp. 77

[2] Z. P. Li: Heilongjiang Researches on Higher Education vol. 3 (2005), pp. 22

[3] Z. P. Li: Education Exploration vol. 4 (2005), pp. 38

[4] Z. P. Li and et al: Journal of Harbin University vol. 10 (2005), pp. 64 